\section{Case report}

Prof. Dr. Md. Abdul Kadir BDS, DDS

Professor and Head of Department Science of Dental Materials University Dental College \& Hospital, Dhaka.

Prof. Dr. Mahbuba Jahan BDS, DDS

Professor and Head of Department Science of Dental Materials City Dental College \& Hospital, Dhaka.

\title{
Intentional Replantation of Molar Tooth A Case Report of 14 Years old Girl
}

\begin{abstract}
:
A case of extensively decayed of right lower 1st molar tooth with a filling was extracted first and then it was treated by root canal filling outside of the mouth and reinserted into the socket and immobilized by inter-dental wiring in October, 1992. It had been reported in 2006 that the treated tooth was healthy without any complaint of patient. The success of intentional replantation procedure appears to be better in younger age.
\end{abstract}

Key Words : Molar tooth, Intentional replantation, Younger age.

\section{Introduction :}

Tooth replantation is the reinsertion and splinting of a tooth that has been avulsed (knocked or torn out) of its socket. And intentional replantation is meant by the intentional extraction of a tooth which is reinserted into its original socket. The purpose of replantation is to prevent permanent loss of the tooth, and to restore the landscape of the mouth so that the patient can eat and speak normally. Conservation of teeth by intentional replantation is being carried out in dentistry for many years. This procedure should be considered as it is the only alternative to tooth extraction. In this procedure extraction of the selected tooth should be done very carefully to avoid damage to the periodontal ligament, cementum without touching root surface. Then endodontic treatment should be done outside of the mouth and inserted into the socket. The tooth to be replanted should be grinded out before extraction, so that the implanted tooth will be less traumatized from masticatory stress after fixation. The aim of this report is to described the success of intentional replantaion at an early age.

\section{Case Report :}

A girl aged 14 years came to author's clinic on 6th October in 1992 with the complaints of swelling in the right side of the lower jaw associated with pain noticed for last 5 months. Intraoral examination revealed that a large amalgam filling on right lower molar ( \# 46) tooth with a reddened buccal gum swelling, slight mobility and tenderness. Other teeth found normal with a bad oral hygien. Other systems revealed no significant abnormalities. The patient was visited by several dental surgeon. She and her guardian became exausted and intended to extract the tooth. But they were motivated to preserve the tooth by intentional replantation.

\section{Radiographic Findings:}

A periapical view of \# 46 showed filling touching the pulp horn with a minimum periapical lesion.

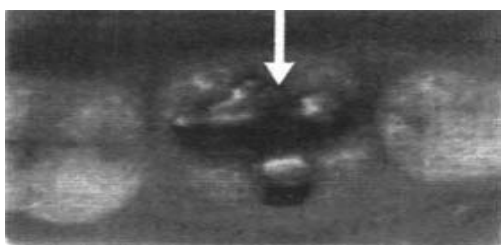

Fig-1 : Showing a filling on right lower 1st molar tooth

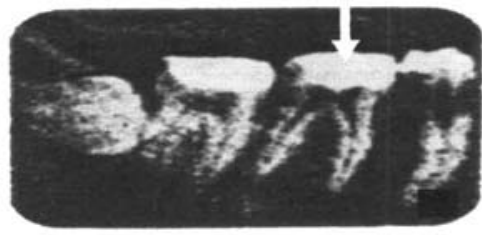

Fig-2 : Showing an $\mathrm{x}$-ray of right lower 1st molar tooth. (periapical view)

With the clinical and radiographic findings the diagnosis was made as a case of chronic closed pulpitis with periapical abscess. 
Treatment Procedure and Results:

Based on the radiographic and clinical diagnosis, the following treatment plan was furnished.

In 1st day, pus was drained intracanally and through gingival crevice under mandibular nerve block local anaesthesia and surface anaesthesia. The tooth was trimmed out occlusally for not to be traumatized by bite, then antibiotic (amoxycillin, 250mg, 8 hourly for 7 days) and analgesic (Paracetamol $500 \mathrm{mg}$, thrice daily for pain relief) were prescribed. In 2nd day, scaling and polishing was done, pus drained, the canal \& crevicular area was irrigated with diluted $\mathrm{H}_{2} \mathrm{O}_{2}$ solution and followed by normal saline.

In the 3rd day the tooth was extracted under local anaesthesia as atraumatically as possible and was held in a piece of sterile gauze saturated with normal saline. Then root canal treatment of the tooth was carried out carefully outside of the mouth in through and through method with guttapercha point. After completion of endonontic treatment, the tooth was kept into a dapen glass of normal saline.

Extracted socket was then inspected, granulation tissue was removed carefully by small spoon curette and the socket was finally irrigated with normal saline. The extracted tooth was replanted in its original socket and immobilized with inter-dental wiring for 4 weeks. Then the inter-dental wiring was removed and a follow up radiograph was taken. The patient did not give any complaint and the radiograph showed apparent attachment of the tooth to the socket. After four and a half month of operations a porcelain fused to metal (PFM) crown was furnished on the tooth. Afterwards, a six monthly follow up was performed. Lastly, the patient came to the clinic in July, 2006 and she was completely allright.

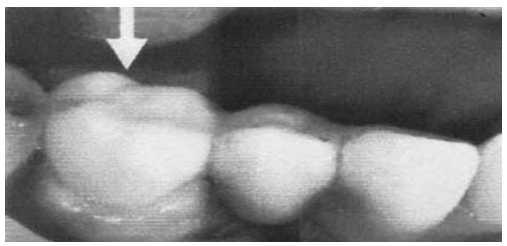

Fig-3 : Showing a porcelain fused to metal (PFM) crown furnished on replanted tooth (\# 46)

\section{Discussion :}

In normal healing a coagulum forms in the socket between the two parts of severed periodontal ligament following replantaiton. Generally after 3-4 days, the gap is obliterated by young connective tissue and in the next two weeks additional collagen fibres develop and complete repair of the periodontal ligaments occurs after 4-6 weeks of operation [1,2,5, 9].
In some cases granulation tissue may be formed in the socket which leads to resorption of roots and bone. The ultimately ankylosis and inflammatory resorption occur [11].

Differences of opinion exist concerning the desirability of retaining the periodontal ligament still attached to the extracted tooth.

Some authors believe that the success of retention of the replanted tooth is proportional to the amount of vital periodontal ligament on the tooth at the time of replantation [1]. Other claim that there is no advantages in retaining the periodontal ligament [4].

Experimental studies of Loe $\mathrm{H}$ and Waerhaug shows if the tooth is replanted just after extraction, maintaining the vitality of periodontal ligament, ankylosis and resorption do not occur 3. Nasjleti et. al. reported that resorption and ankylosis were not observed in intentional replanted teeth in monkeys in 3 weeks to 4 months time [2].

The periodontal ligament (PDL) is that soft, spicialized connective tissue situated between the cementum covering the root of the tooth and the bone forming the socket wall. It's average width is $0.21 \mathrm{~mm}$ at 11 to 16 years of age, $0.18 \mathrm{~mm}$ at 32 to 52 years, and $0.15 \mathrm{~mm}$ at 51 to 67 years, showing a progressive decrease with age [8].

The principal cells of the PDL are fibroblasts. Fibroblasts originate from mesenchymal cells. Once differentiated, fibroblasts can replicate by mitotic cell division (as seen in wound repair and in in vitro cultures of fibroblasts populations). When fibroblasts from embryonic tissue are cultured, however, they are able to undergo about 50 divisions before they become senescent and die. This number is reduced to 20 when fibroblasts from adult tissue are cultured. This suggests correlation between age and life span of the fibroblast $[8,9]$.

The above description indicates that there is a relation between tissue repair and age. It means repair is better in early age than older age.

\section{Conclusion:}

From the above discussion it may be concluded that the extracted tooth becomes attached completely to the alveolar bone when intentional replantation can be done sooner after extraction. The success of the operation appears to be better in early age.

\section{Acknowledgement :}

The Author acknowledges to Prof. Dr. Md. Zahid Hossain PhD. Department of Periodontology and Oral Pathology, University Dental College \& Hospital, Dhaka for his kind cooperation and assistance. 


\section{Reference :}

1. Kingsbury BS Jr, Weisenbaugh. JM Jr. Intentional replantation of Mandibular Molar \& premolar J.A. DA. 1971; 83:1053.

2. Nasjleti CE, Caffesse RG, Castelli WA, and Hoke JA. Healing after tooth replantations in monkeys Oral Surg. 1975; 39:361.

3. Loe $\mathrm{H}$ and Waerhaug - Experimental replantation of teeth in dog and monkeys Arch Oral Biol. 1961; 3: 176.

4. Andreasen JO, Hjorting Hanseon E. Replantation of teeth Acta Odontol. Second. 1966; 24:263.

5. Messing JJ. Replantation of teeth. Dent. Practit. 1968; 18: 241.

6. Andreasen JO. Hjorting HE. Replantation of teeth. In: Radiographic and clinical study of 110 human teeth replanted after accidental loss. Acta Odontol scaued. 1966; 24: 263.

7. Andreasen JO. Periodontal healing after replanting of traumatically avulsed human teeth. Assessment mobility testing and radiography. Acta Odontol Scand. 1975; 33: 325.

8. Mc Culloch CAG. Borden S. Role of fibroblast sub-populations in periodontal physiology and pathology. J Periodont Res. 1991; 26: 144.

9. Richard Ten Cate. Oral Histology. Development, Structure, and Function. 5th ed. St. Louis:Mosby; 1998.

10. Pitt Ford TR. Harty's Endodontics in Clinical Practice. 4th ed. Wright, Oxford. 1997.

11. Andreasen JO. Relationship between cell damage in periodontal ligament after replantation and subsequent of root resorptions. A time related study in monkeys. Acta Odontol scand. 1981; 39: 15. 